\title{
Thiol protecting agents and antioxidants inhibit the mitochondrial permeability transition promoted by etoposide: implications in the prevention of etoposide-induced apoptosis
}

\author{
José B.A. Custódio a,b,*, Carla M.P. Cardoso a, \\ Leonor M. Almeida a,b \\ ${ }^{a}$ Laboratório de Bioquímica, Faculdade de Farmácia, Universidade de Coimbra, Couraça dos Apóstolos, \\ 51, r/c 3 000-295 Coimbra, Portugal \\ ${ }^{\mathrm{b}}$ Centro de Neurociências de Coimbra, Universidade de Coimbra, Couraça dos Apóstolos, 51, \\ r/c 3 000-295 Coimbra, Portugal
}

Received 4 December 2001; received in revised form 10 March 2002; accepted 15 March 2002

\begin{abstract}
Etoposide (VP-16) is known to promote cell apoptosis either in cancer or in normal cells as a side effect. This fact is preceded by the induction of several mitochondrial events, including increase in $\mathrm{Bax} / \mathrm{Bcl}-2$ ratio followed by cytochrome $c$ release and consequent activation of caspase- 9 and -3 , reduction of ATP levels, depolarization of membrane potential $(\Delta \Psi)$ and rupture of the outer membrane. These events are apoptotic factors essentially associated with the induction of the mitochondrial permeability transition (MPT). VP-16 has been shown to stimulate the $\mathrm{Ca}^{2+}$-dependent MPT induction similarly to prooxidants and to promote apoptosis by oxidative stress mechanisms, which is prevented by glutathione (GSH) and $N$-acetylcysteine (NAC). Therefore, the aim of this work was to study the effects of antioxidants and thiol protecting agents on MPT promoted by VP-16,
\end{abstract}

Abbreviations: Asc, ascorbic acid; CyA, cyclosporine A; DTT, dithiothreitol; $\Delta \Psi$, mitochondrial membrane potential; EGTA, ethylene glycol-bis( $\beta$-aminoethyl ether) $N N N^{\prime} N^{\prime}$-tetraacetic acid; GSH, glutathione; HEPES, 4-(2-hydroxymethyl)-1-piperazineethanesulfonic acid; MPT, mitochondrial permeability transition; Mn-SOD, Mn-superoxide dismutase; NAC, $N$-acetylcysteine; NEM, $N$-ethylmaleimide; $\mathrm{TPP}^{+}$, tetraphenylphosphonium; VP-16, etoposide.

* Corresponding author. Tel.: + 351-239-852564; fax: + 351-239-852569.

E-mail address: custodio@ci.uc.pt (J.B.A. Custódio). 
attempting to identify the underlying mechanisms on VP-16-induced apoptosis. The increased sensitivity of isolated mitochondria to $\mathrm{Ca}^{2+}$-induced swelling, $\mathrm{Ca}^{2}+$ release, depolarization of $\Delta \Psi$ and uncoupling of respiration promoted by VP-16, which are prevented by cyclosporine A proving that VP-16 induces the MPT, are also efficiently prevented by ascorbate, the primary reductant of the phenoxyl radicals produced by VP-16. The thiol reagents GSH, dithiothreitol and $N$-ethylmaleimide, which have been reported to prevent the MPT induction, also protect this event promoted by VP-16. The inhibition of the VP-16-induced MPT by antioxidants agrees with the prevention of etoposide-induced apoptosis by GSH and NAC and suggests the generation of oxidant species as a potential mechanism underlying the MPT that may trigger the release of mitochondrial apoptogenic factors responsible for apoptotic cascade activation. (C) 2002 Elsevier Science Ireland Ltd. All rights reserved.

Keywords: Etoposide; Anticancer; Apoptosis; Mitochondrial permeability transition; Antioxidants; Oxidative stress

\section{Introduction}

Etoposide (VP-16), a semisynthetic derivative of podophyllotoxin, is an anti-tumor effective single agent also currently used as an important component of the chemotherapeutic approach to a variety of hematopoietic and solid tumors [1].

VP-16 is a cytotoxic agent by either interacting directly with macromolecular targets or by generating reactive oxygen $\left(\mathrm{O}_{2}\right)$ species (ROS) [2,3]. Recently, it has been reported that its cytotoxicity is mediated by triggering mitochondrial events that seem to be obligatory steps of early (pre-nuclear) apoptosis. Such events include the release of cytochrome $c$ from mitochondria and disruption of outer membrane due to mitochondrial permeability transition (MPT) induction [4,5], which precedes the activation of caspase 9 and 3 [6,7], the reduction of mitochondrial membrane potential $(\Delta \Psi)$ and the formation of ultracondensed mitochondria [8]. The destructive effects on the outer membrane integrity, with subsequent release of the intermembrane apoptogenic factors from mitochondria, could also suggest the involvement of VP-16-induced MPT on the activation of apoptotic cascade $[9,10]$. Moreover, different studies confirm that cells treated with MPT inducers alone undergo apoptosis and that, at least in most models of apoptosis, the induction of MPT and mitochondrial cytochrome $c$ release are essential components of the apoptotic pathway [11-13]. On the other hand, cells undergoing VP-16-induced apoptosis, which is prevented by glutathione (GSH) and $N$-acetylcysteine (NAC) [7], also evidence a significant increase in the generation of ROS [14], mitochondrial NO production [15] and induction of MnSOD [16]. Furthermore, VP-16 induces peroxide formation and depletion of GSH in cells during the apoptotic process [17], suggesting the occurrence of GSH oxidation or cleavage of the catalytic subunit of $\gamma$-glutamilcysteine synthetase [17], probably due to the intermediate formation of hydroxyl and phenoxyl radicals [2,3].

Therefore, considering that the oxidation of thiol groups by ROS and/or other oxidants, in addition to other oxidative stress mechanisms, has been proposed as a critical factor regulating the induction of the MPT [18,19] and apoptosis [20,21], the 
mechanisms underlying VP-16-promoted apoptosis may involve cellular oxidative stress and MPT induction. Ascorbate (Asc), GSH and protein thiols are known to be major intracellular reductants that may reduce the VP-16 phenoxyl radicals, preventing its cytotoxic effects [3]. Thus, the aim of this work was to study the effects of two major water-soluble intracellular antioxidants, Asc and GSH, and of the thiol protecting agents, dithiothreitol (DTT) and $N$-ethylmaleimide (NEM), on VP-16-induced MPT to clarify the underlying mechanisms of MPT induction by this drug and its potential relationship with the reported prevention of VP-16-induced apoptosis by GSH and NAC [7].

\section{Materials and methods}

\subsection{Chemicals}

Etoposide (VP-16), 4-(2-hydroxymethyl)-1-piperazineethanesulfonic acid (HEPES), ascorbic acid, glutathione, DTT, bovine serum albumin (BSA), cyclosporine (CyA) and oligomycin were purchased from Sigma Chemical Co. (St. Louis, MO). Ethylene glycol-bis( $\beta$-aminoethyl ether) $N N N^{\prime} N^{\prime}$-tetraacetic acid (EGTA), tetraphenylphosphonium $\left(\mathrm{TPP}^{+}\right)$and sucrose were from Merck (Darmstadt, Germany). All the other chemicals were of research grade. Solutions were prepared in deionized ultra pure water.

\subsection{Rat liver mitochondria}

Hepatic mitochondria were isolated from Wistar rats $(200-300 \mathrm{~g})$ by differential centrifugation [22]. The liver was quickly homogenized with a glass Potter-type homogenizer and Teflon pestle in ice-cold isolation medium containing $250 \mathrm{mM}$ sucrose, $10 \mathrm{mM}$ HEPES (pH 7.4) and $1 \mathrm{mM}$ EGTA, supplemented with $0.1 \%$ BSA. The homogenate was centrifuged at $800 \times g$ for 10 min at $4{ }^{\circ} \mathrm{C}$. The mitochondrial pellet was recovered from the supernatant by centrifugation at $10000 \times g$ for 10 min and was washed twice in the ice-cold isolation medium adjusted to $\mathrm{pH} 7.2$ in the absence of EGTA and BSA. Fresh mitochondria with a respiratory control ratio (RCR) (state 3/state 4 respiration) of about 5 were used within $4 \mathrm{~h}$ for all assays.

\subsection{Standard incubation procedure}

Mitochondria were suspended in a standard reaction medium containing $200 \mathrm{mM}$ sucrose, $10 \mathrm{mM}$ Tris-Mops ( $\mathrm{pH}$ 7.4), $1 \mathrm{mM} \mathrm{KH}_{2} \mathrm{PO}_{4}$ and $10 \mu \mathrm{M}$ EGTA, supplemented with $2 \mu \mathrm{M}$ rotenone and $0.5 \mu \mathrm{g}$ oligomycin $/ \mathrm{ml}$. VP-16, prepared in dimethyl sulfoxide and diluted in standard reaction medium immediately prior each experiment, was added to the reaction medium after protein addition and incubated for $5 \mathrm{~min}$ before starting the reactions. Where indicated by the arrows, $1 \mu \mathrm{M} \mathrm{CyA}$, $40 \mu \mathrm{M}$ NEM, Asc, GSH and DTT $(1 \mu \mathrm{mol} / \mathrm{mg}$ protein $)$ were added prior to VP-16 
incubation with mitochondria. The results represent typical recordings from experiments of at least three different mitochondrial preparations.

\subsection{Mitochondrial swelling}

Mitochondrial osmotic volume changes were followed by monitoring continuously the decrease in apparent absorbance (light-scattering) at $540 \mathrm{~nm}$ as described elsewhere [23], except that mitochondria $(0.5 \mathrm{mg}$ protein $/ \mathrm{ml})$ in $2 \mathrm{ml}$ of reaction medium were supplemented with $140 \mathrm{nmol} \mathrm{Ca}^{2+} / \mathrm{mg}$ protein before energization with succinate. In addition, negative controls for GSH and Asc effects were carried out by pre-incubating the mitochondria with mixtures of oxidized GSH (GSSG) plus GSH peroxidase and dehydroascorbic acid (DHA) plus Asc oxidase, respectively.

\subsection{Measurement of mitochondrial membrane potential}

Estimation of membrane potential $(\Delta \Psi)$ was performed using a $\mathrm{TPP}^{+}$-sensitive electrode prepared according to Kamo et al. [24]. Mitochondria (1 mg/2 ml) were suspended in the reaction medium supplemented with $4 \mu \mathrm{M} \mathrm{TPP}^{+}$and energized with $5 \mathrm{mM}$ succinate. After a steady-state distribution of $\mathrm{TPP}^{+}$has been reached (ca. $2 \mathrm{~min}$ of recording), $\mathrm{Ca}^{2+}(200 \mathrm{nmol} / \mathrm{mg}$ protein) was added and $\Delta \Psi$ recorded for 12 additional minutes. Mitochondrial $\Delta \Psi$ was evaluated by the transmembrane distribution of $\mathrm{TPP}^{+}$as previously described $[23,25]$.

\subsection{Mitochondrial $\mathrm{Ca}^{2+}$ fluxes and $\mathrm{O}_{2}$ consumption}

Mitochondrial $\mathrm{Ca}^{2+}$ fluxes and $\mathrm{O}_{2}$ consumption were evaluated in parallel in the same mitochondrial preparation. The changes in $\mathrm{Ca}^{2+}$ fluxes across the inner mitochondrial membrane were monitored using a $\mathrm{Ca}^{2+}$-sensitive electrode according to previously described procedures $[23,26]$ and $\mathrm{O}_{2}$ uptake was estimated with a Clark-type electrode (Yellow Springs Instrument Co., Model YSI 5331) as described elsewhere [27]. The reactions were performed with $1 \mathrm{mg}$ protein in $1 \mathrm{ml}$ of the reaction medium and the experiments were started with $5 \mathrm{mM}$ succinate after 1 min of $\mathrm{Ca}^{2+}$ addition (180 nmol/mg protein) in the absence and presence of VP-16.

\subsection{Simultaneous evaluation of $\Delta \Psi$ and $\mathrm{O}_{2}$ consumption}

The effects of VP-16 on the mitochondrial respiration and $\Delta \Psi$ were measured simultaneously at $25{ }^{\circ} \mathrm{C}$ in $1 \mathrm{ml}$ of the respiratory medium containing $130 \mathrm{mM}$ sucrose, $50 \mathrm{mM} \mathrm{KCl}, 5 \mathrm{mM} \mathrm{MgCl} 2,0.1 \mathrm{mM}$ EGTA, $5 \mathrm{mM} \mathrm{KH_{2 }} \mathrm{PO}_{4}, 5 \mathrm{mM}$ Hepes, $\mathrm{pH} 7.4,2 \mu \mathrm{M}$ rotenone and $4 \mu \mathrm{M} \mathrm{TPP}^{+} . \mathrm{O}_{2}$ consumption was monitored polarographically with a Clark-type electrode and $\Delta \Psi$ was measured with a $\mathrm{TPP}^{+}$ electrode, as described before, inserted in the same closed $\mathrm{O}_{2}$ reaction chamber. Mitochondria ( $1 \mathrm{mg}$ ) were energized with $5 \mathrm{mM}$ succinate and, after steady-state distribution of $\mathrm{TPP}^{+}$, ADP (150 nmol/mg protein) was added to initiate state 3 
respiration and $\mathrm{O}_{2}$ concentration and $\Delta \Psi$ were monitored continuously until resumption of state 4 .

\section{Results}

The effects of antioxidants and thiol compounds on mitochondrial swelling induced by VP-16, as monitored spectrophotometrically at $540 \mathrm{~nm}$, are shown in Fig. 1. As we have previously reported [5], VP-16 $(1 \mu \mathrm{mol} / \mathrm{mg}$ protein $-500 \mu \mathrm{M})$ increases the sensitivity of mitochondria to undergo a rapid and large decrease in the absorbance due to MPT induced by $\mathrm{Ca}^{2+}(140 \mathrm{nmol} / \mathrm{mg}$ protein) (Fig. 1, trace 1) since it is prevented by CyA $(1 \mu \mathrm{M})$ (Fig. 1, trace 7$)$, a potent and specific inhibitor of the MPT. The VP-16 concentrations used to promote MPT were relatively high as compared to those reported in pre-incubations with cells for $24-48 \mathrm{~h}$ to induce apoptosis [7,14,17]. Actually, since these incubation times are not feasible in mitochondrial studies, our experiments were carried out with higher VP-16 concentrations, as also reported by other studies $(0.25$ to $2 \mathrm{mM})[2,3,28,29]$, but incubated with mitochondria only for $5 \mathrm{~min}$ before starting the reactions. Therefore, a dose-response curve of VP-16 was performed to calculate the drug

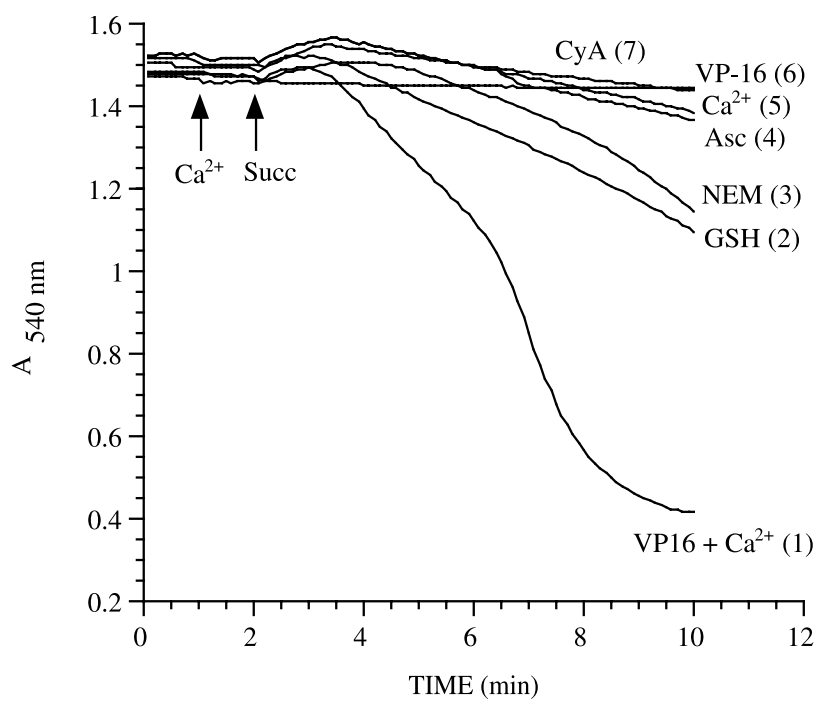

Fig. 1. Inhibitor effects of Asc, glutathione (GSH) and NEM on VP-16-induced $\mathrm{Ca}^{2+}$-dependent mitochondrial swelling. Mitochondria $(0.5 \mathrm{mg}$ protein $/ \mathrm{ml})$ incubated at $30^{\circ} \mathrm{C}$ in $2 \mathrm{ml}$ of standard reaction medium, supplemented with $2 \mu \mathrm{M}$ rotenone and $0.5 \mu \mathrm{g}$ oligomycin $/ \mathrm{ml}$, were energized with 5 $\mathrm{mM}$ succinate after addition of either VP-16 $\left(1 \mu \mathrm{mol} / \mathrm{mg}\right.$ protein) $(6), \mathrm{Ca}^{2}+(140 \mathrm{nmol} / \mathrm{mg}$ protein) (5) or VP-16 plus $\mathrm{Ca}^{2+}(1)$. Asc $(1 \mathrm{mM})(4)$, GSH $(1 \mathrm{mM})(2)$ and NEM $(40 \mu \mathrm{M})(3)$ were pre-incubated with mitochondria before addition of VP-16 and their protective effects were compared to that afforded by CyA $(1 \mu \mathrm{M})(7)$. Mitochondrial swelling was followed continuously by the light-scattering at $540 \mathrm{~nm}$ and the traces are typical direct recordings from three to four separate experiments. 
concentrations able to increase the sensitivity of isolated mitochondria to $\mathrm{Ca}^{2+}$-induced swelling due to MPT induction. The minor concentration $(1 \mu \mathrm{mol} / \mathrm{mg}$ protein-500 $\mu \mathrm{M}$ ) was used in experiments of $\mathrm{Ca}^{2+}$-dependent MPT induction.

The extensive VP-16-induced swelling observed when mitochondria are incubated with VP-16 plus $\mathrm{Ca}^{2+}$ (Fig. 1, trace 1) is completely prevented by pre-incubating the mitochondria, prior to VP-16 addition, with either Asc ( $1 \mu \mathrm{mol} / \mathrm{mg}$ protein) (Fig. 1, trace 4), the primary reductant of the phenoxyl radical of etoposide [3], or GSH (1 $\mu \mathrm{mol} / \mathrm{mg}$ protein) (Fig. 1, trace 2) but, at the same concentrations, GSH shows a lower protective effect than Asc. Noteworthy that their oxidized forms, GSSG and DHA, did not show any suppressive effects on VP-16-induced MPT (results not shown), according to the reported absence of effects on VP-16-induced apoptosis. The monofunctional sulfhydryl alkylating agent NEM (40 $\mu \mathrm{M})$ (Fig. 1, trace 3) has a similar effect to GSH in preventing VP-16-induced mitochondrial swelling. The fact that the effects of VP-16 are prevented by Asc, GSH and NEM, but not by DHA and GSSG, suggests the involvement of oxidative events, as reported to other MPT inducers whose action mechanism has been recognized to be mediated by dithiol and pyridine nucleotides oxidation [30,31].

The induction of MPT involving oxidative stress generated by VP-16 is further evidenced in Fig. 2 that reports the effects of this drug on mitochondrial membrane potential $(\Delta \Psi)$. Adding $\mathrm{Ca}^{2+}$, at the concentration of $200 \mathrm{nmol} / \mathrm{mg}$ protein, to energized mitochondria with succinate causes an immediate, yet transient, depolarization of $\Delta \Psi$ that recovers within $2.5 \mathrm{~min}$ (Fig. 2, trace 1). In the presence of VP-16 (Fig. 2, trace 2), $\mathrm{Ca}^{2+}$ promotes a gradual and irreversible depolarization of $\Delta \Psi$, which is completely prevented by CyA (Fig. 2, trace 3) added to mitochondria before VP-16 incubation, as we have previously reported [5]. Similarly, the addition of either Asc (Fig. 2, trace 4) or GSH (Fig. 2, trace 5), the two major water-soluble intracellular antioxidants, as also the thiol protecting agent DTT $(1 \mu \mathrm{mol} / \mathrm{mg}$ protein) (Fig. 2, trace 6) to mitochondria before the pre-incubation with VP-16 affords complete protection against the $\mathrm{Ca}^{2+}$-induced irreversible depolarization of $\Delta \Psi$.

Further evidence for the oxidative events as a mechanism underlying VP-16-induced MPT is also provided by the complete protection of those compounds against both the release of loaded $\mathrm{Ca}^{2+}$ (Fig. 3) and the uncoupling of $\mathrm{Ca}^{2+}$-stimulated respiration (Fig. 4) caused by VP-16. Mitochondria energized with succinate accumulate and retain $\mathrm{Ca}^{2+}$ taken up within about $20 \mathrm{~min}$ (Fig. 3, trace 1). In accordance with the results of mitochondrial swelling and $\Delta \Psi$ referred above, mitochondria previously exposed to VP-16 for $5 \mathrm{~min}$ at $30{ }^{\circ} \mathrm{C}$ are unable to sustain the loaded $\mathrm{Ca}^{2+}$, occurring an irreversible release of the accumulated $\mathrm{Ca}^{2+}$ (Fig. 3, trace 2) which is completely prevented by CyA (Fig. 3, trace 5) that affords to mitochondria complete capacity to accumulate and retain the sequestered $\mathrm{Ca}^{2+}$. The addition of either DTT (Fig. 3, trace 3), GSH (Fig. 3, trace 4) or Asc (Fig. 3, trace 6) to mitochondria before VP-16 also provides full protection against the $\mathrm{Ca}^{2+}$-induced irreversible release of the mitochondrial $\mathrm{Ca}^{2+}$-loaded. The protective effect of Asc (Fig. 3, trace 6) against the VP-16-induced actions is remarkable and Asc-treated mitochondria can withstand successive additions of $\mathrm{Ca}^{2+}$, in a total of about 300 nmol without becoming uncoupled or releasing the $\mathrm{Ca}^{2+}$ taken up. 


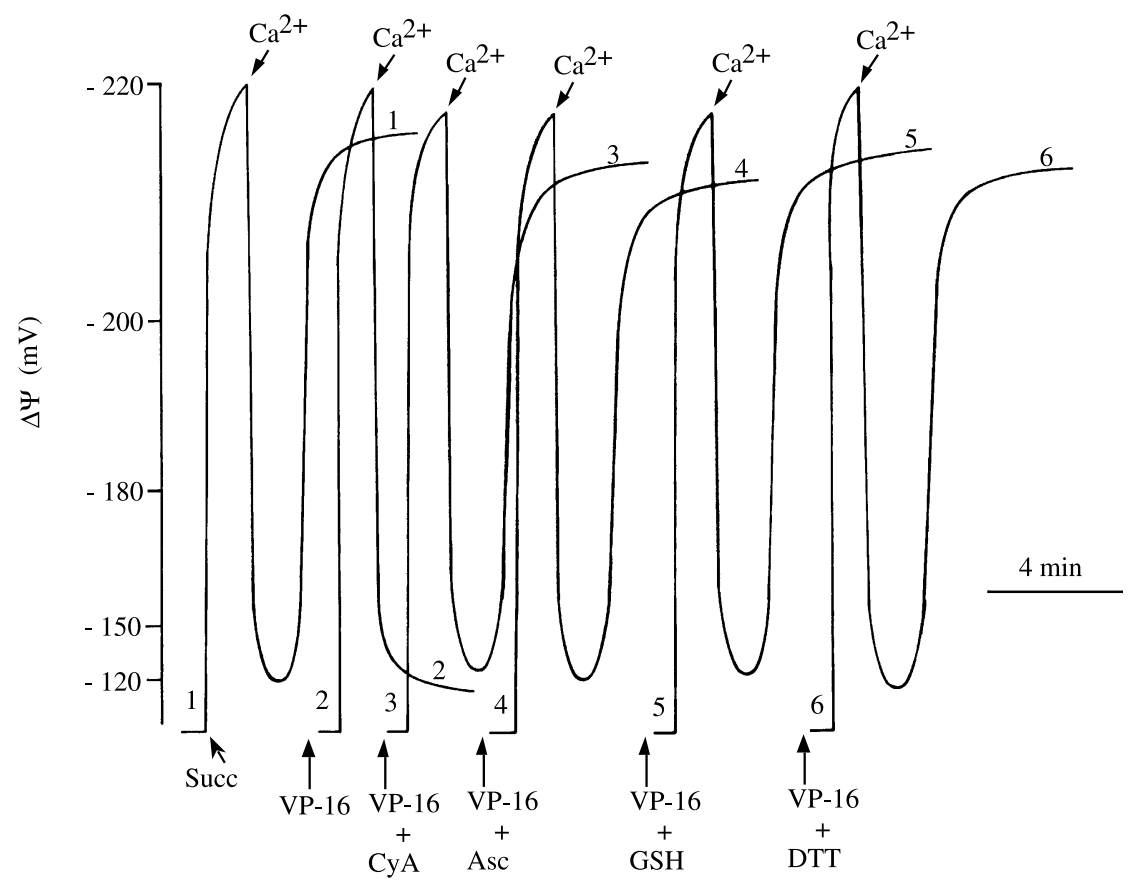

Fig. 2. Protection against VP-16-induced irreversible depolarization of $\Delta \Psi$ by Asc, glutathione (GSH) and DTT. Mitochondria, at $0.5 \mathrm{mg}$ protein $/ \mathrm{ml}$, in the standard reaction medium supplemented with 2 $\mu \mathrm{M}$ rotenone, $0.5 \mu \mathrm{g}$ oligomycin $/ \mathrm{ml}$ and $4 \mu \mathrm{M} \mathrm{TPP}{ }^{+}$were incubated at $30{ }^{\circ} \mathrm{C}$ and $\Delta \Psi$ was recorded continuously using a $\mathrm{TPP}^{+}$selective electrode, as described in Section 2. The reactions were initiated with $5 \mathrm{mM}$ succinate and after a steady-state distribution of $\mathrm{TPP}^{+}$either in the absence (1) or presence of $1 \mu \mathrm{mol} \mathrm{VP}-16 / \mathrm{mg}$ protein incubated with mitochondria for $5 \mathrm{~min}$ (2) $\mathrm{Ca}^{2+}$ was added $(200 \mathrm{nmol} / \mathrm{mg}$ protein). CyA (1 $\mu \mathrm{M})(3)$, Asc (4), GSH (5) and DTT (6), at concentrations of $1 \mu \mathrm{mol} / \mathrm{mg}$ protein, were pre-incubated with mitochondria before adding VP-16. The recordings are typical of three independent experiments.

Fig. 4 shows the effects of VP-16 on respiration at the same reaction conditions as described to Fig. 3, depicting mitochondrial $\mathrm{Ca}^{2+}$ fluxes. Adding $\mathrm{Ca}^{2+}(180$ $\mathrm{nmol} / \mathrm{mg}$ protein) to mitochondria induces stimulation of the $\mathrm{O}_{2}$ consumption, which returns to state 4 after repolarization of $\Delta \Psi$ (Fig. 2, trace 1) and accumulation of the added $\mathrm{Ca}^{2+}$ (Fig. 3, trace 1), as we have previously reported [5]. However, mitochondria pre-incubated for 5 min with VP-16 undergo complete uncoupling of respiration after addition of $\mathrm{Ca}^{2+}$ (Fig. 4, trace 2), which parallels the irreversible depolarization of $\Delta \Psi$ (Fig. 2, trace 2) and release of the $\mathrm{Ca}^{2+}$ accumulated (Fig. 3, trace 2). Addition of either DTT (Fig. 4, trace 3), GSH (Fig. 4, trace 4) or Asc (Fig. 4, trace 5) to mitochondria, prior to the pre-incubation with the drug, completely prevents the uncoupling of $\mathrm{Ca}^{2+}$-stimulated mitochondrial respiration caused by VP-16. Worthy of notice is that although NEM prevents the VP-16-induced mitochondrial swelling, it dramatically reduces the accumulation of $\mathrm{Ca}^{2+}$ (Fig. 3, trace 7) and the transient stimulation of respiration by $\mathrm{Ca}^{2+}$ (Fig. 4, 
trace 6), as previously described [22], suggesting particular effects on either the $\mathrm{Ca}^{2+}$ transport or the $\mathrm{Ca}^{2+}$-dependent respiratory pathways as a consequence of the inhibition of phosphate transport protein.

As shown above (Fig. 3, trace 6), the efficiency of Asc in protection of mitochondria against VP-16-induced $\mathrm{Ca}^{2}+$ release is noticeable. Actually, Asc mimics CyA (Fig. 5), a specific MPT inhibitor that increases dramatically the capacity of mitochondria to accumulate $\mathrm{Ca}^{2+}$ without succumbing to uncoupled respiration (Fig. 5). This clearly suggests that Asc prevents the thiol groups' oxidation or other oxidative events putatively involved in the MPT induced by VP-16 due to the generation of oxidant species.

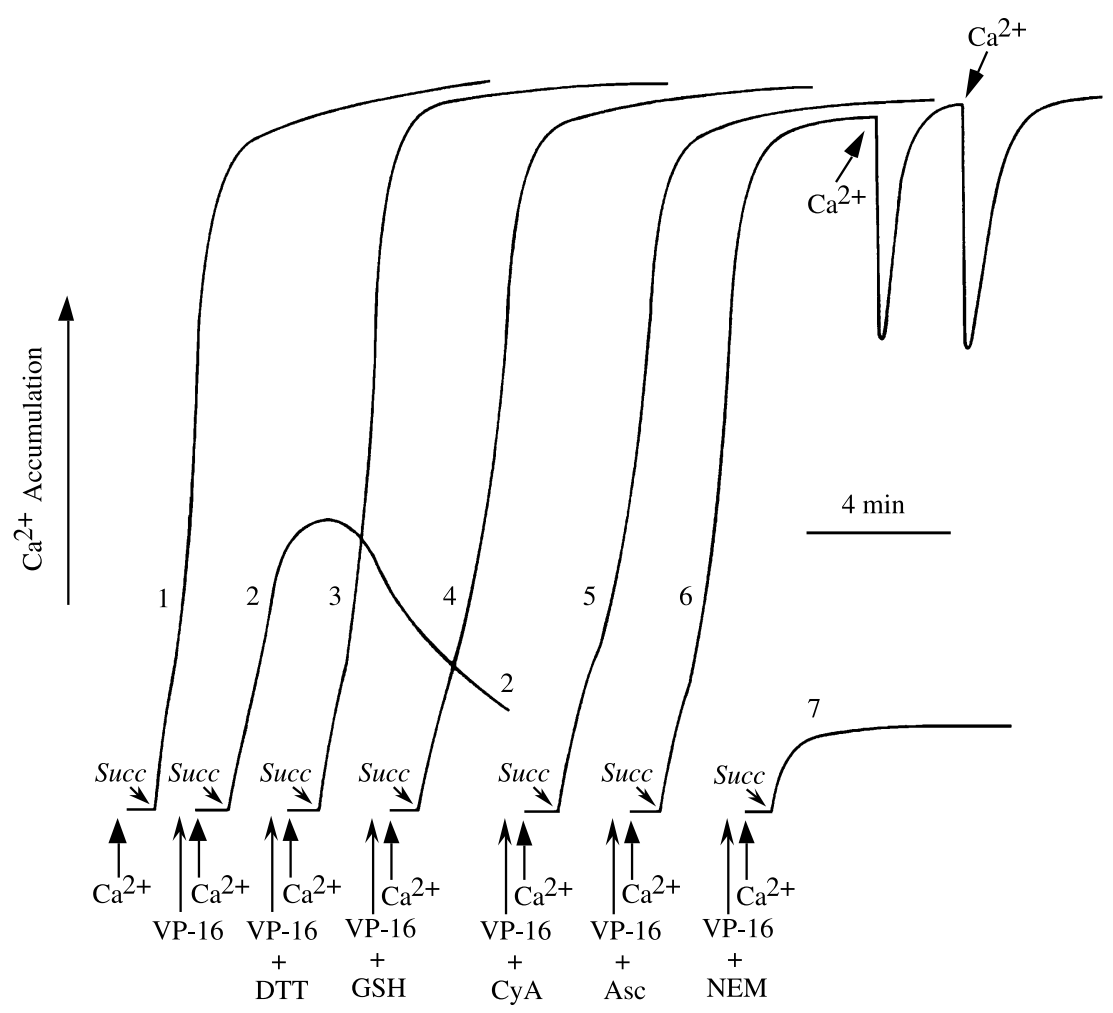

Fig. 3. Inhibitory effects of Asc, glutathione (GSH), DTT and NEM on mitochondrial $\mathrm{Ca}^{2+}$ release associated with MPT induced by VP-16. Mitochondria were incubated for $5 \mathrm{~min}$ at $30{ }^{\circ} \mathrm{C}$ in the standard reaction medium in the absence (1) and presence of VP-16 (2). Where indicated, DTT (3), GSH (4), CyA (5), Asc (6), at concentrations indicated in legend to Fig. 2, and NEM (40 $\mu \mathrm{M})$ (7) were pre-incubated with mitochondria before addition of VP-16. Following the pre-incubation period, $\mathrm{Ca}^{2+}$ was added $(180 \mathrm{nmol} / \mathrm{mg}$ protein) and mitochondria were energized with $5 \mathrm{mM}$ succinate. The uptake of $\mathrm{Ca}^{2+}$ and the release of sequestered $\mathrm{Ca}^{2+}$ by mitochondria were monitored continuously with a $\mathrm{Ca}^{2+}$-selective electrode. In the experiment with Asc (6), mitochondria were supplemented with successive additions of $40 \mathrm{nmol} \mathrm{Ca}{ }^{2+} / \mathrm{mg}$ protein. All traces are representative of 3-4 independent experiments. 


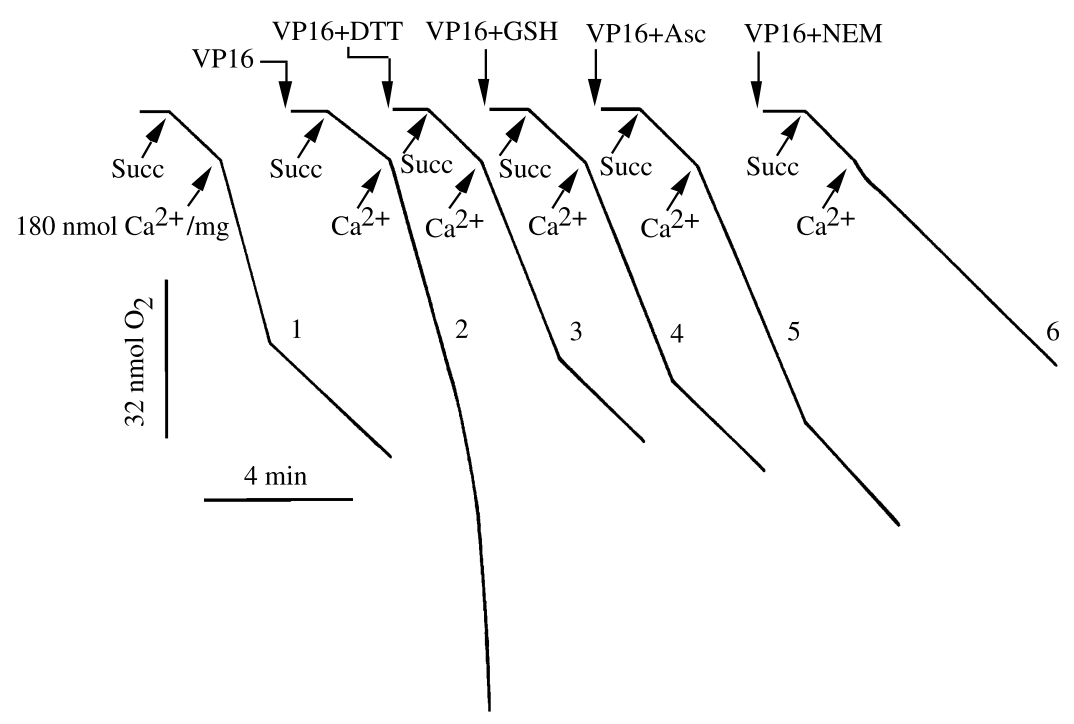

Fig. 4. Prevention of VP-16-induced mitochondrial respiration uncoupling by either DTT, glutathione (GSH), Asc, or NEM. Mitochondria, at $0.5 \mathrm{mg} \operatorname{protein} / \mathrm{ml}$, in the standard reaction medium supplemented with $2 \mu \mathrm{M}$ rotenone and $0.5 \mu \mathrm{g}$ oligomycin $/ \mathrm{ml}$, were incubated at $30{ }^{\circ} \mathrm{C}$ in the absence (1) and presence (2) of VP-16 $\left(1 \mu \mathrm{mol} / \mathrm{mg}\right.$ protein). $\mathrm{O}_{2}$ consumption was monitored using a Clarke-type $\mathrm{O}_{2}$ electrode placed in a closed reaction chamber. DTT (3), GSH (4), Asc (5) or NEM (6) were pre-incubated with mitochondria before VP-16 addition. The traces represent typical recordings from three separate experiments with different mitochondrial preparations.

The concentrations of VP-16 used in these experiments neither affect significantly the $\Delta \Psi$ (Fig. 6) nor the respiratory chain (Fig. 7), as evaluated simultaneously with a $\mathrm{TPP}^{+}$and an $\mathrm{O}_{2}$-sensitive electrodes, respectively, placed in the same closed reaction chamber. The pre-incubation of mitochondria with VP-16 depresses slightly the total developed $\Delta \Psi$ as compared with the FCCP-induced depolarization (Fig. 6). The depressive effect of VP-16, with a maximum depolarization degree of about $-35 \mathrm{mV}$ to $2 \mu \mathrm{mol} / \mathrm{mg}$ protein (Fig. 6), associated with the changes on the phosphorylation cycle induced by ADP suggest that VP-16 does not significantly affect the phosphorylation capacity of mitochondria. In fact, VP-16, at concentrations used to induce MPT $(1 \mu \mathrm{mol} / \mathrm{mg}$ protein -500 $\mu \mathrm{M}$ ), does not alter either state-3 or -4 respiration (Fig. 7), indicating that RCR of mitochondria is not sensitive to these drug concentrations. Moreover, the $\mathrm{ADP} / \mathrm{O}$ ratio, as a measure of the efficiency of mitochondrial oxidative phosphorylation, is not changed (Fig. 7). However, at concentrations of 1.5 and $2 \mu \mathrm{mol} /$ mg protein, VP-16 lengthens the lag phase preceding repolarization (Fig. 6) and induces a moderate decrease in $\mathrm{ADP} / \mathrm{O}$ and $\mathrm{RCR}$ indexes (Fig. 7), proving the slightly depressive effect on the phosphorylation efficiency of mitochondria. 


\section{Discussion}

Mitochondria undergo a $\mathrm{Ca}^{2+}$-dependent MPT that has been implicated in different cell functions [32,33] and in the mechanisms of toxic tissue injury caused by different compounds [34,35], playing a central role in the activation of necrosis and apoptosis pathways [6,9,36,37].

The MPT induction is strongly regulated by both $\Delta \Psi$ and $\Delta \mathrm{pH}$ components of the mitochondrial protonmotive force, divalent cations and different metabolites [38], in addition to the thiol redox status of cysteine residues in the vicinity of the voltage sensor of the pore that determines the probability of MPT induction $[18,19,30]$. Moreover, the MPT possesses at least two redox-sensitive sites, one of them in equilibrium with GSH of mitochondrial matrix and another that can be

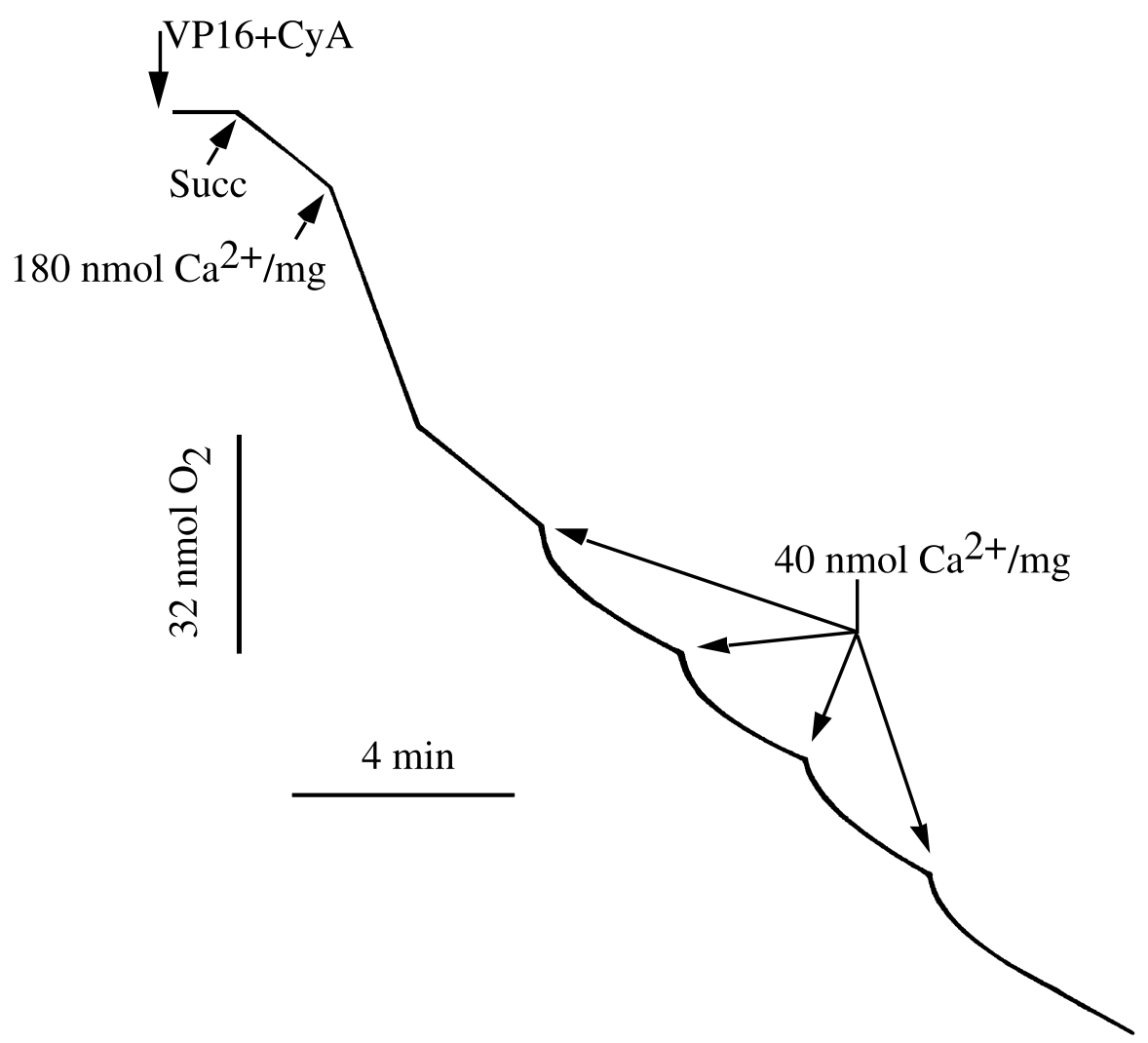

Fig. 5. Prevention of VP-16-induced mitochondrial respiration uncoupling by CyA. $\mathrm{O}_{2}$ consumption was monitored as described in the legend to Fig. 4 using a Clarke-type $\mathrm{O}_{2}$ electrode. Mitochondria were pre-incubated with CyA $(1 \mu \mathrm{M})$ before addition of VP-16 $(1 \mu \mathrm{mol} / \mathrm{mg}$ protein $)$. After energization with succinate (Succ) mitochondria were loaded with $180 \mathrm{nmol} \mathrm{Ca}^{2+} / \mathrm{mg}$ protein and supplemented with successive additions of $40 \mathrm{nmol} \mathrm{Ca}{ }^{2} / \mathrm{mg}$ protein. The traces represent typical recordings from at least three independent experiments. 


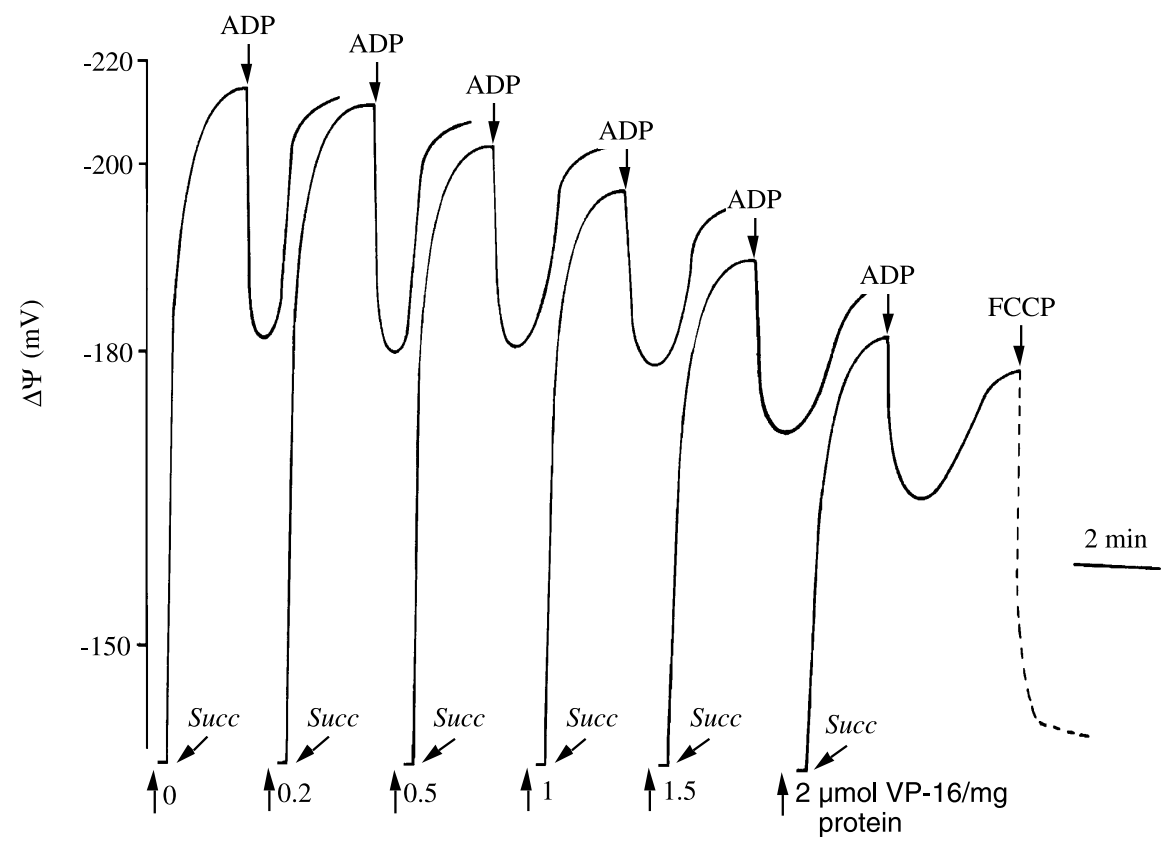

Fig. 6. Effect of VP-16 concentration on the mitochondrial transmembrane potential $(\Delta \Psi)$. Mitochondria $(1 \mathrm{mg})$ suspended in the respiratory medium supplemented with $4 \mu \mathrm{M} \mathrm{TPP}{ }^{+}$and $2 \mu \mathrm{M}$ rotenone were energized with $5 \mathrm{mM}$ succinate (Succ) after incubation at $25{ }^{\circ} \mathrm{C}$ for $5 \mathrm{~min}$ in the presence of different VP-16 concentrations ( $\mu$ mol VP-16/mg protein) indicated by the values adjacent to the traces. Mitochondrial $\Delta \Psi$ was evaluated with a $\mathrm{TPP}^{+}$selective electrode placed in a closed reaction chamber as described in Section 2. ADP $(150 \mathrm{nmol} / \mathrm{mg}$ protein) was added after a steady-state distribution of $\mathrm{TPP}^{+}$to induce state 3 respiration. The addition of FCCP $(1 \mu \mathrm{M})$ after ADP phosphorylative cycle promotes the depolarization of $\Delta \Psi$. The recordings are typical of 3-4 independent experiments.

directly activated by ROS [30]. Therefore, in addition to the oxidation of membrane protein sulfhydryl groups, the oxidation of both GSH and NAD(P)H of mitochondrial matrix [30], followed closely by an increase in the mitochondrial $\mathrm{Ca}^{2+}$ and ROS generation within mitochondria (or a decreasing in their detoxification), contributes to the MPT induction, as shown by studies with several MPT inducers, including tert-butylhydroperoxide [39-42] and inorganic phosphate [31,43]. Besides the generation of ROS, NO can also act on mitochondria amplifying the signals promoting the MPT $[44,45]$.

On the other hand, in vitro studies have shown that VP-16 is an effective scavenger of peroxyl radicals [28], in agreement with its capacity to inhibit the $\mathrm{NAD}(\mathrm{P}) \mathrm{H} /$ daunomicin-induced lipid peroxidation in liver microsomes [46]. However, the oxidation of VP-16 leads to the formation of phenoxyl radicals [2,3], that promote selective oxidation of protein thiols [28], and to the generation of ROS [14-17]. Ascorbate and several thiols reduce the VP-16-derived phenoxyl radicals, as indicated by electron spin resonance and thiol oxidation measurements [3,28]. Moreover, the prevention of VP-16-induced apoptosis by GSH and NAC [7], an 
antioxidant and precursor of GSH, suggests that an oxidative shift in the cell redox state and/or an increase in generation of oxidant species should be implicated in the mechanisms underlying the cell death induced by this drug. Therefore, VP-16-promoted oxidative events, including the oxidation of $\mathrm{NAD}(\mathrm{P}) \mathrm{H}, \mathrm{GSH}$ and specific protein thiols, could contribute to trigger the MPT induction. This hypothesis is supported by our observation that Asc, which reduces the phenoxyl radical of VP-16 [3] and inhibits the thiol oxidation induced by this drug [28], prevents the VP-16-induced mitochondrial swelling (Fig. 1), depolarization of $\Delta \Psi$ (Fig. 2), $\mathrm{Ca}^{2+}$ release (Fig. 3) and uncoupling of respiration (Fig. 4), the events that characterize the MPT induction. Moreover, these effects are also prevented by GSH (Figs. 1-4) which, besides several cellular functions [47,48], plays a pivotal role in the regulation of apoptosis [49], inhibiting the VP-16-induced apoptosis [7]. Similar inhibitor effects on these mitochondrial events are caused by the thiol protecting agent DTT (Figs. 1-4) that like NEM has been demonstrated to provide strong protection against oxidant-induced increases in the voltage gating of the MPT [18,19]. However, the protection provided by NEM against the mitochondrial swelling (Fig. 1, trace 3) and its induced decrease in the $\mathrm{Ca}^{2+}$-stimulation of respiration (Fig. 4, trace 6) may be in part due to the partial inhibition of phosphate (Pi) carrier and to the consequent decrease in the accumulation of $\mathrm{Ca}^{2+}$ (Fig. 3, trace 7) required to trigger the MPT induction. In addition, it should be taken into account its effects

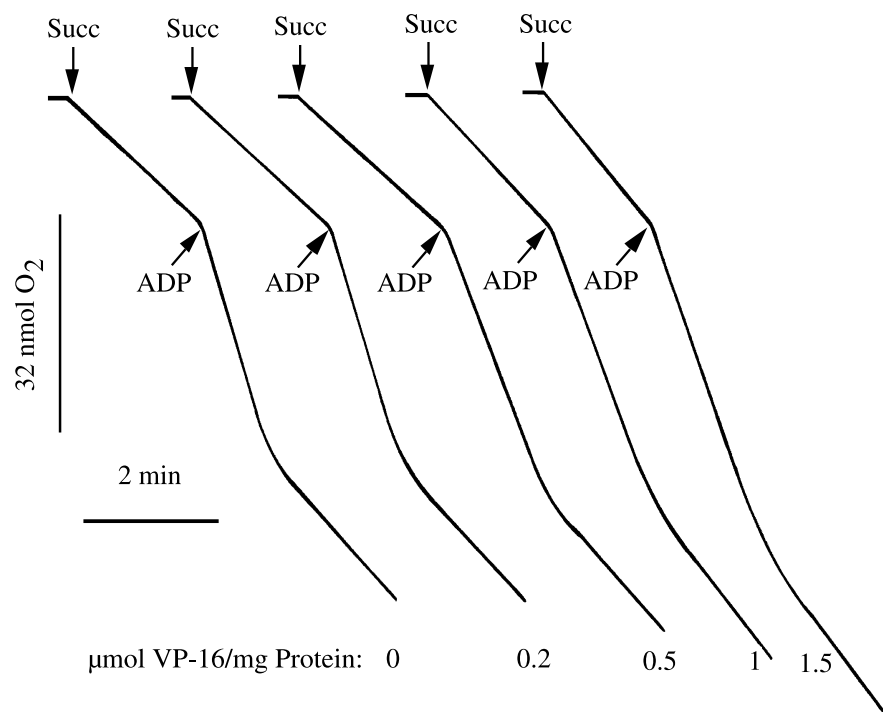

Fig. 7. Effect of VP-16 concentration on the mitochondrial $\mathrm{O}_{2}$ consumption. $\mathrm{O}_{2}$ consumption was monitored as described in the legend to Fig. 6, using a Clarke-type $\mathrm{O}_{2}$ electrode placed in the same closed reaction chamber. Mitochondria $(1 \mathrm{mg})$ suspended in the respiratory medium were energized with $5 \mathrm{mM}$ succinate (Succ) after incubation at $25{ }^{\circ} \mathrm{C}$ for $5 \mathrm{~min}$ in the presence of different VP-16 concentrations ( $\mu \mathrm{mol} \mathrm{VP}-16 / \mathrm{mg}$ protein) indicated by the values adjacent to the traces. ADP (150 $\mathrm{nmol} / \mathrm{mg}$ protein) was added to induce state 3 respiration. The recordings are typical of three independent experiments. 
either on the thiol redox status $[18,42,43,50]$ of the MPT or on the mitochondrial bioenergetics, as previously reported [22].

Noteworthy that VP-16 increases the sensitivity of isolated mitochondria to the $\mathrm{Ca}^{2+}$-induced depolarization of $\Delta \Psi$ (Fig. 2), and promotes the uncoupling of $\mathrm{Ca}^{2+}$-stimulated mitochondrial respiration (Fig. 4), without significant effect on $\Delta \Psi$ (Fig. 6), respiratory control and $\mathrm{ADP} / \mathrm{O}$ ratios (Fig. 7) in the absence of $\mathrm{Ca}^{2+}$. Taken together, these results demonstrate that VP-16 decreases the $\Delta \Psi$ of mitochondria putatively due to a futile cycling of either protons or potassium ions, as also suggested by Robertson et al. [4], being unable to act as a mobile proton carrier (Figs. 6 and 7) in contrast to the hypothetic mitochondrial uncoupling effect of VP-16 proposed elsewhere [4]. Consequently, the effects of VP-16, at the concentrations used in this study, are probably due to a direct action on the $\mathrm{Ca}^{2+}$-dependent MPT megachannel complex.

Since the compounds that prevent the VP-16-induced MPT do not affect the mitochondrial functional activities, our data, taken together with those on the oxidative stress effects of VP-16 in cells undergoing apoptosis [7,14,16] and on VP-16-induced oxidation of protein thiol groups [28], suggest that MPT promoted by VP-16 is related to oxidative stress caused by oxidant species generated by this drug $[2,3]$, leading to changes in the redox status of mitochondrial NAD $(\mathrm{P}) \mathrm{H}, \mathrm{GSH}$ and protein thiol groups oxidation.

Studies concerning the involvement of oxidative stress in apoptosis have also provided evidence that ROS play an important role in the signaling mechanisms for the default pathway of apoptosis. Moreover, ROS have also been implicated on the release of cytochrome $c$ and other apoptosis-inducing factors, as well as on the upstream of caspases involved in the apoptotic cascade [10,51-53]. Although it has been reported that in cytochrome $c$-induced cell death, cytochrome $c$ release may occur by both MPT-dependent and independent mechanisms, several studies have shown that MPT and cytochrome $c$ release are early events in several model of apoptosis $[4,6,7,19,54]$. Moreover, the pro-apoptotic protein Bax, implicated in the release of cytochrome $c$, has been suggested to translocate from the cytosol to mitochondria in cells under the action of VP-16, a process that is prevented by the anti-apoptotic protein Bcl-2 [53], which inhibits the MPT by keeping the pyridine nucleotides in a relative reduced state [42,55]. Therefore, in cells undergoing VP-16-induced apoptosis, it has been shown an increase in the Bax/Bcl-2 ratio, followed by cytochrome $c$ release and caspase- 9 and -3 activation, and its inhibition by GSH and NAC [7]. Such observations, together with our data, point to the generation of oxidant species promoted by VP-16 as a mechanism underlying the induction of MPT and the promotion of apoptosis.

In conclusion, this work provides evidence that oxidative stress plays an important role in the induction of the MPT by VP-16, according to its oxidant effects in cells undergoing apoptosis. Triggering of the MPT by VP-16, leading to mitochondrial swelling (causing mechanical disruption of the outer membrane and release of apoptogenic factors), depolarization of $\Delta \Psi$, uncoupling of respiration (reducing ATP levels) and mitochondrial $\mathrm{Ca}^{2+}$ release (a prerequisite for post-mitochondrial events involved in caspase activation), could be regarded as a key pathway involved in apoptosis induced by VP-16. 


\section{Acknowledgements}

This work was supported by Portuguese FCT-Research Project Sapiens 99/ $36075 / 99$.

\section{References}

[1] P.J. O’Dwyer, B. Leyland-Jones, M.T. Alonso, S. Marsoni, R.E. Wittes, Etoposide (VP-16-213). Current status of an active anticancer drug, New Eng. J. Med. 312 (1985) 692-700.

[2] B. Kalyanaraman, J. Nemec, B.K. Sinha, Characterization of free radicals produced during oxidation of etoposide (VP-16) and its catechol and quinone derivatives. An ESR study, Biochemistry 28 (1989) 4839-4846.

[3] V.E. Kagan, J.C. Yalowich, B.W. Day, R. Goldman, T.G. Gantchev, D.A. Stoyanovsky, Ascorbate is the primary reductant of the phenoxyl radical of etoposide in the presence of thiols both in cell homogenates and in model systems, Biochemistry 33 (1994) 9651-9660.

[4] J.D. Robertson, V. Gogvadge, B. Zhivotovski, S. Orrenius, Distinct pathways for stimulation of cytochrome c release by etoposide, J. Biol. Chem. 275 (2000) 32 438-32 443.

[5] J.B.A. Custódio, C.M.P. Cardoso, V.M.C. Madeira, L.M. Almeida, Mitochondrial permeability transition induced by the anticancer drug etoposide, Toxicol. in Vitro 15 (2001) 265-270.

[6] Q. Chen, B. Gong, A. Almasan, Distinct stages of cytochrome c release from mitochondria: evidence for feedback amplification loop linking caspase activation to mitochondrial dysfunction in genotoxic stress induced apoptosis, Cell Death Differ. 7 (2000) 227-233.

[7] M. Sawada, S. Nakashima, Y. Banno, H. Yamakawa, K. Hayashi, K. Takenaka, Y. Nishimura, N. Sakai, Y. Nozawa, Ordering of ceramide formation, caspase activation, and Bax/Bcl-2 expression during etoposide-induced apoptosis in C6 glioma cells, Cell Death Differ. 7 (2000) 761-772.

[8] J. Zhuang, D. Dinsdale, G.M. Cohen, Apoptosis, in human monocytic THP1 cells, results in the release of cytochrome $\mathrm{c}$ from mitochondria prior to their ultracondensation, formation of outer membrane discontinuities and reduction in inner membrane potential, Cell Death Differ. 5 (1988) 953-962.

[9] T. Hirsch, D. Decaudin, S.A. Susin, P. Marchetti, N. Larochette, M. Resche-Rigon, G. Kroemer, PK11195, a ligand of the mitochondrial benzodiazepine receptor, facilitates the induction of apoptosis and reverses Bcl-2-mediated cytoprotection, Exp. Cell Res. 241 (1998) 426-434.

[10] P.X. Petit, M. Goubern, P. Diolez, S.A. Susin, N. Zamzami, G. Kroemer, Disruption of the outer mitochondrial membrane as a result of large amplitude swelling: the impact of irreversible permeability transition, FEBS Lett. 426 (1998) 111-116.

[11] T. Hirsch, P. Marchetti, S.A. Susin, B. Dallaporta, N. Zamzami, I. Marzo, M. Geauskens, G. Kroemer, The apoptosis-necrosis paradox. Apoptogenic proteases activated after mitochondrial permeability transition determine the mode of cell death, Oncogene 15 (1997) 1573-1581.

[12] J.G. Pastorino, S.T. Chen, M. Tafani, J.W. Snyder, J.L. Farber, The overexpression of Bax produces cell death upon induction of the mitochondrial permeability transition, J. Biol. Chem. 273 (1998) 7770-7775.

[13] M. Tafani, T.G. Schneider, J.G. Pastorino, J.L. Farber, Cytochrome c-dependent activation of caspase- 3 by tumor necrosis factor requires induction of the mitochondrial permeability transition, Am. J. Pathol. 156 (2000) 2111-2121.

[14] C.L. Perkins, G. Fang, C.N. Kim, K.N. Bhalla, The role of Apaf-1, caspase 9, and bid proteins in etoposide- or paclitaxel-induced mitochondrial events during apoptosis, Cancer Res. 15 (2000) $1645-1653$.

[15] J. Bustamante, G. Bersier, M. Romero, R.A. Badin, A. Boveris, Nitric oxide production and mitochondrial dysfunction during rat thymocyte apoptosis, Arch. Biochem. Biophys. 376 (2000) $239-247$. 
[16] P. Mantymaa, T. Siitonen, T. Guttorm, M. Saily, V. Kinnula, E.R. Savoilainen, P. Koistinen, Induction of mitochondrial manganese superoxide dismutase confers resistance to apoptosis in acute myeloblastic leukaemia cells exposed to etoposide, Br. J. Haematol. 108 (2000) 574-581.

[17] T. Siitonen, P. Alaruikka, P. Mantymaa, E.R. Savolainen, T.J. Kavanagh, C.M. Krejsa, C.C. Franklin, V. Kinnula, P. Koistinen, Protection of acute myeloblastic leukemia cells against apoptotic cell death by high glutathione and gama-glutamylcysteine synthetase during etoposide-induced oxidative stress, Ann. Oncol. 10 (1999) 1361-1367.

[18] V. Petronilli, P. Costantini, L. Scorrano, R. Colonna, S. Passamonti, P. Bernardi, The voltage sensor of the mitochondrial permeability transition pore is tunel by the oxidation-reduction state of vicinal thiols, J. Biol. Chem. 269 (1994) 16638-16642.

[19] V. Petronilli, A. Nicolli, P. Costantini, R. Colonna, P. Bernardi, Regulation of the permeability transition pore, a voltage-dependent mitochondrial channel inhibited by cyclosporine A, Biochim. Biophys. Acta 1187 (1994) 255-259.

[20] J. Chandra, A. Samali, S. Orrenius, Triggering and modulation of apoptosis by oxidative stress, Free Radical Biol. Med. 29 (2000) 323-333.

[21] J. Cai, D.C. Wallace, B. Zhivotovski, D.P. Jones, Peroxynitrite formed by mitochondrial NO synthase promotes mitochondrial $\mathrm{Ca}^{2+}$ release, Free Radical Biol. Med. 29 (2000) 334-342.

[22] J.B.A. Custódio, C.M. Palmeira, A.J.M. Moreno, K.B. Wallace, Acrylic acid induces the glutathione-independent mitochondrial permeability transition in vivo, Toxicol. Sci. 43 (1998) 19-27.

[23] J.B.A. Custódio, A.J.M. Moreno, K.B. Wallace, Tamoxifen inhibits induction of mitochondrial permeability transition by $\mathrm{Ca}^{2+}$ and inorganic phosphate, Toxicol. Appl. Pharmacol. 152 (1998) $10-17$.

[24] N. Kamo, M. Muratsugu, R. Hongoh, V. Kobatake, Membrane potential of mitochondria measured with an electrode sensitive to tetraphenylphosphonium and relationship between proton electrochemical potential and phosphorylation potential in steady state, J. Membr. Biol. 49 (1979) $105-121$.

[25] A.J.M. Moreno, V.M.C. Madeira, Mitochondrial bioenergetics as affected by DTT, Biochim. Biophys. Acta 1060 (1991) 166-174.

[26] V.M.C. Madeira, A rapid and ultrasensitive method to measure $\mathrm{Ca}^{2+}$ movements across biological membranes, Biochem. Biophys. Res. Commun. 64 (1975) 870-876.

[27] J.B.A. Custódio, T.C.P. Dinis, L.M. Almeida, V.M.C. Madeira, Tamoxifen and hydroxytamoxifen as intramembraneous inhibitors of lipid peroxidation. Evidence for peroxyl radical scavenging activity, Biochem. Pharmacol. 47 (1994) 1989-1998.

[28] V.B. Ritov, R. Goldman, D.A. Stoyanovski, E.V. Menshikova, V.E. Kagan, Antioxidant paradoxes of phenolic compounds: peroxyl radical scavenger and lipid antioxidant, etoposide (VP-16), inhibits sarcoplasmic reticulum $\mathrm{Ca}^{2+}$-ATPase via thiol oxidation by its phenoxyl radical, Arch. Biochem. Biophys. 321 (1995) 140-152.

[29] D. Stoyanovski, J. Yalowich, T. Gantchev, V. Kagan, Tyrosinase-induced phenyl radicals of etoposide (VP-16): interaction with reductants in model systems, K562 leikemic cell and nuclear homogenates, Free Radical Res. Commun. 19 (1993) 371-386.

[30] P.C. Constantini, B.C. Chernyak, V. Petronilli, P. Bernardi, Modulation of the mitochondrial permeability transition pore by pyridine nucleotides and dithiol oxidation at two separate sites, $\mathrm{J}$. Biochem. Biol. 271 (1996) 6746-6751.

[31] A.J. Kowaltovski, L.E.S. Netto, A.E. Vercesi, The thiol-specific antioxidant enzyme prevents mitochondrial permeability transition. Evidence for the participation of reactive oxygen species, J. Biol. Chem. 273 (1998) 12 766-12769.

[32] P. Bernardi, V. Petronilli, The permeability transition pore as a mitochondrial calcium release channel: a critical appraisal, J. Bioenerg. Biomembr. 28 (1996) 131-138.

[33] P. Bernardi, The permeability transition pore. Control points of a cyclosporine A-sensitive mitochondrial channel involved in cell death, Biochim. Biophys. Acta 1275 (1996) 5-9.

[34] M. Zoratti, I. Szabo, The mitochondrial permeability transition, Biochim. Biophys. Acta 141 (1995) $139-176$.

[35] K.B. Wallace, J.T. Eells, V.M.C. Madeira, G. Cortopassi, D.P. Jones, Mitochondria-mediated cell injury, Fundam. Appl. Toxicol. 38 (1997) 23-37. 
[36] P. Bernardi, R. Colonna, P. Constantini, O. Erikson, E. Fontaine, F. Ichas, S. Massari, A. Nicolli, V. Petronilli, L. Scorrano, The mitochondrial permeability transition, Biofactors 8 (1998) 273-281.

[37] F. Ichas, J.-P. Mazat, From calcium signaling to cell death: two conformations for the mitochondrial permeability transition. Switching from low- to high-conductance state, Biochim. Biophys. Acta 1366 (1998) 33-50.

[38] P. Bernardi, K.M. Broekemeier, D.R. Pfeiffer, Recent progress on regulation of the mitochondrial permeability transition pore, a cyclosporine-sensitive pore in the inner mitochondrial membrane, $\mathrm{J}$. Bioenerg. Biomembr. 26 (1994) 509-517.

[39] R.F. Castilho, A.J. Kowaltovski, A.R. Meinicke, E.J.H. Bechara, A.E. Vercesi, Permeabilization of the inner mitochondrial membrane by $\mathrm{Ca}^{2+}$ ions is stimulated by $t$-butylhydroperoxide and mediated by reactive oxygen species generated by mitochondria, Free Radical Biol. Med. 18 (1995) 479-486.

[40] A.-L. Nieminen, A.K. Saylor, S.A. Tesfai, B. Herman, J.J. Lemasters, Contribution of the mitochondrial permeability transition to lethal injury after exposure of hepatocytes to $t$-butylhydroperoxide, Biochem. J. 307 (1995) 99-106.

[41] A.-L. Nieminen, A.M. Byrne, B. Herman, J.J. Lemasters, Mitochondrial permeability transition in hepatocytes induced by $t$-BuOOH: NAD(P)H and reactive oxygen species, Am. J. Physiol. 272 (1997) C1286-C1294.

[42] A.J. Kowaltovski, A.E. Vercesi, G. Fiskum, Bcl-2 prevents mitochondrial permeability transition and cytochrome c release via maintenance of reduced pyridine nucleotides, Cell Death Differ. 7 (2000) 903-910.

[43] A.J. Kowaltovski, R.F. Castilho, M.T. Grijalba, E.J.H. Bechara, A.E. Vercesi, Effect of inorganic phosphate concentration on the nature of inner mitochondrial membrane alterations mediated by $\mathrm{Ca}^{2}+$ ions. A proposed model for phosphate-stimulated lipid peroxidation, J. Biol. Chem. 271 (1996) 2929-2934.

[44] M.A. Packer, M.P. Murphy, Peroxynitrite causes calcium efflux from mitochondria which is prevented by cyclosporin A, FEBS Lett. 345 (1994) 237-240.

[45] S. Hortelano, B. Dallaporta, N. Zamzami, T. Hirsh, S.A. Susin, I. Marzo, L. Bosca, G. Kroemer, Nitric oxide induces apoptosis via triggering mitochondrial permeability transition, FEBS Lett. 410 (1997) 373-377.

[46] B.K. Sinha, M.A. Trush, Free radical metabolism of VP-16 and inhibition of anthracycline-induced lipid peroxidation, Biochem. Pharmacol. 32 (1983) 3495-3498.

[47] B.A. Arrick, C.F. Nathan, Glutathione metabolism as a determinant of therapeutic efficacy: a review, Cancer Res. 44 (1984) 4224-4232.

[48] J.B. Schulz, J. Lindenau, J. Seyfried, J. Dichgans, Glutathione, oxidative stress and neurodegeneration, Eur. J. Biochem. 267 (2000) 4904-4911.

[49] A.G. Hall, The role of glutathione in the regulation of apoptosis, Eur. J. Clin. Invest. 29 (1999) $238-245$.

[50] P. Constantini, R. Colonna, P. Bernardi, Induction of the mitochondrial permeability transition by $N$-ethylmaleimide depends on secondary oxidation of critical thiol groups. Potentiation by copper-ortho-phenanthroline without dimerization of the adenine nucleotide translocase, Biochim. Biophys. Acta 1365 (1998) 385-392.

[51] W. Lieberthal, V. Triaca, J.S. Koh, P.J. Pagano, J.S. Levine, Role of superoxide in apoptosis induced by growth factor withdrawal, Am. J. Physiol. 275 (1998) F691-F702.

[52] J.J. Lemasters, T. Qian, S.P. Elmore, L.C. Trost, Y. Nishimura, B. Herman, C.A. Bradham, D.A. Brenner, A.-L. Nieminen, Confocal microscopy of the mitochondrial permeability transition in necrotic cell killing, apoptosis and autophagy, Biofactors 8 (1998) 283-285.

[53] J.J. Lemasters, T. Qian, C.A. Bradham, D.A. Brenner, W.E. Cascio, L.C. Trost, Y. Nishimura, A.-L. Nieminen, B. Herman, Mitochondrial dysfunction in the pathogenesis of necrotic and apoptotic cell death, J. Bioenerg. Biomembr. 31 (1999) 305-319.

[54] K.M. Murphy, V. Ranganathan, M.L. Farnsworth, M. Kavallaris, R.B. Lock, Bcl-2 inhibits Bax translocation from cytosol to mitochondria during drug-induced apoptosis of human tumor cells, Cell Death Differ. 7 (2000) 102-111.

[55] M.D. Espositi, I. Htzinisiriou, H. McLennan, S. Ralph, Bcl-2 and mitochondrial oxygen radicals. New approaches with reactive oxygen-sensitive probes, J. Biol. Chem. 274 (1999) 29831-29837. 